\title{
Calcium-Dependent Regulation of Rab3 in Short-Term Plasticity
}

\author{
Frédéric Doussau, ${ }^{1}$ Aude Clabecq, ${ }^{2}$ Jean-Pierre Henry, ${ }^{2}$ François Darchen, ${ }^{2}$ and Bernard Poulain ${ }^{1}$ \\ ${ }^{1}$ Laboratoire de Neurobiologie Cellulaire, UPR 9009, Centre National de la Recherche Scientifique, F-67084 Strasbourg \\ Cedex, France, and 2 Service de Neurobiologie Physico-Chimique, Centre National de la Recherche Scientifique, ERS \\ 575, Institut de Biologie Physico-Chimique, F-75005 Paris, France
}

The Rab3 proteins are monomeric GTP-binding proteins associated with secretory vesicles. In their active GTP-bound state, Rab3 proteins are involved in the regulation of hormone secretion and neurotransmitter release. This action is thought to involve specific effectors, including two $\mathrm{Ca}^{2+}$-binding proteins, Rabphilin and Rim. Rab3 acts late in the exocytotic process, in a cell domain in which the intracellular $\mathrm{Ca}^{2+}$ concentration is susceptible to rapid changes. Therefore, we examined the possible $\mathrm{Ca}^{2+}$-dependency of the regulatory action of GTP-bound Rab3 and wild-type Rab3 on neuroexocytosis at identified cholinergic synapses in Aplysia californica. The effects of recombinant GTPase-deficient Aplysia-Rab3 (apRab3-Q80L) or wild-type apRab3 were studied on evoked acetylcholine release. Intraneuronal application of apRab3-Q80L in identified neurons of the buccal ganglion of Aplysia led to inhibition of neurotransmission; wild-type apRab3 was less effective. Intracellular chelation of $\mathrm{Ca}^{2+}$ ions by EGTA greatly potentiated the inhibitory action of apRab3-Q80L. Train and paired-pulse facilitation, two $\mathrm{Ca}^{2+}$-dependent forms of short-term plasticity induced by a rise in intraterminal $\mathrm{Ca}^{2+}$ concentration, were increased after injection of apRab3-Q80L. This result suggests that the inhibition exerted by GTP-bound Rab3 on neuroexocytosis is reduced during transient augmentations of intracelIular $\mathrm{Ca}^{2+}$ concentration. Therefore, $\mathrm{a} \mathrm{Ca}^{2+}$-dependent modulation of GTP-bound Rab3 function may contribute to shortterm plasticity.

Key words: Aplysia; synapse; synaptic vesicle exocytosis; neurotransmitter release mechanism; Rab3; facilitation; posttetanic potentiation; synaptic plasticity
Neurotransmitter release involves $\mathrm{Ca}^{2+}$-triggered exocytosis of synaptic vesicle contents. Despite recent progress, the molecular events underlying this physiological process have not yet been deciphered (for review, see Südhof, 1995; Calakos and Scheller, 1996; Matthews, 1996; Zucker, 1996). Rab3 is implicated in the regulation of $\mathrm{Ca}^{2+}$-dependent hormone and neurotransmitter exocytosis (Lledo et al., 1993; Geppert et al., 1994, 1997; Holz et al., 1994; Johannes et al., 1994, 1996; Regazzi et al., 1996; Weber et al., 1996; Nonet et al., 1997); however, its role is still unresolved.

Rab3 is a small G-protein of the Rab/Ypt1/Sec4 family that is highly conserved in all eukaryotes and is implicated in intracellular vesicle transport and fusion with target membranes (Novick and Zerial, 1997; Südhof, 1997). Rab3 proteins are strongly expressed in neuroendocrine cells and neurons, where they are specifically localized on secretory granules and synaptic vesicles (Darchen et al., 1990, 1995; Fischer von Mollard, 1990, 1991, 1994; Regazzi et al., 1996). In the cytosol, Rab3 is bound to GDP, whereas on the vesicle, Rab3 is mostly in the GTP-bound state.

Received Sept. 15, 1997; revised Feb. 13, 1998; accepted Feb. 17, 1998.

This work was supported by research contracts from the Association Française de Lutte contre les Myopathies (B.P., J.-P.H., F.D), the Fondation pour la Recherche Médicale (B.P.), and the Association pour la Recherche sur le Cancer (J.-P. H.). We thank Dr. Y. Hu, Dr. R. Baston, and Dr. E. R. Kandel for the cDNA encoding Aplysia-Rab3, M. P. Laran-Chich for technical assistance, Dr. L. Johannes for his help in the starting of this study, Dr. A. Feltz, Dr. J. L. Bossu, and Dr. T. Galli for critical reading of this manuscript, and Dr. N. Grant for revising this manuscript.

This paper is dedicated to Dr. Alberto Mallart on the occasion of the anniversary of his pioneering studies on synaptic facilitation and his retirement from Centre National de la Recherche Scientifique.

Correspondence should be addressed to Bernard Poulain, Laboratoire de Neurobiologie Cellulaire, Centre National de la Recherche Scientifique, 5 rue B. Pascal, F-67084 Strasbourg Cedex, France.

Copyright (C) 1998 Society for Neuroscience $\quad 0270-6474 / 98 / 183147-11 \$ 05.00 / 0$
When Rab3 is bound to GTP, it is in an active form, and Rab3 can be complexed with its effectors Rabphilin (Shirataki et al., 1992; McKiernan et al., 1993; Li et al., 1994), Rim (Wang et al., 1997), or the prenylated-Rab acceptor PRA1 (Martincic et al., 1997). When exocytosis is stimulated, GTP is hydrolyzed and GDP-bound Rab3 dissociates from the vesicle membrane (Fisher von Mollard, 1991, 1994; Stahl et al., 1994).

Several steps in the exocytotic process are regulated by $\mathrm{Ca}^{2+}$ ions in the micromolar range, which is far below the concentration required to trigger vesicle fusion (Bittner and Holz, 1992; Hsu et al., 1996). However, the identity of the proteins involved in these steps is still unknown. The regulatory function of Rab3 in exocytosis involves several targets, including Rabphilin and Rim. Both of these proteins possess two $\mathrm{C} 2$ domains, allowing their binding to phospholipids in the presence of micromolar $\mathrm{Ca}^{2+}$ (Yamaguchi et al., 1993; Wang et al., 1997). Our previous work at Aplysia synapses indicated that part of Rab3 action seems to intervene after the docking of synaptic vesicles at release sites (Johannes et al., 1996). Moreover, at hippocampal excitatory CA1 synapses, Rab3A acts downstream from the $\mathrm{Ca}^{2+}$-sensitive step that regulates quantal release probability (Geppert et al., 1997). These observations suggest that Rab3 action occurs in a cell domain in which the intracellular concentration of $\mathrm{Ca}^{2+}$ $\left(\left[\mathrm{Ca}^{2+}\right]_{\mathrm{i}}\right)$ is susceptible to rapid changes. Therefore, the aim of this work was to examine the $\mathrm{Ca}^{2+}$ dependency of the regulatory action of the active GTP-bound state of Rab3 on neuroexocytosis at identified synapses in Aplysia. We used a GTPase-deficient recombinant Aplysia-Rab3 (apRab3-Q80L) that is incorporated in the Rab3 cycle (Johannes et al., 1996). The intracellular actions of apRab3-Q80L and wild-type apRab3 on acetylcholine (ACh) release were examined under conditions in which $\left[\mathrm{Ca}^{2+}\right]_{\mathrm{i}}$ was 
modified. The inhibitory action of apRab3-Q80L was greatly potentiated when $\left[\mathrm{Ca}^{2+}\right]_{\mathrm{i}}$ was decreased. Moreover, our data suggest that part of paired-pulse or train facilitation can be accounted for by a transient removal of the negative clamp exerted by GTP-Rab3 on neuroexocytosis.

\section{MATERIALS AND METHODS}

Electrical recordings. All experiments were performed at $22^{\circ} \mathrm{C}$ at identified synapses in dissected buccal ganglia of Aplysia californica (100-150 gm body weight) (Marinus Inc.). In this ganglion, two presynaptic neurons, B4 and B5, make well characterized cholinergic chloride-dependent inhibitory synapses with the same set of postsynaptic cells that includes B3, B6, and other neurons (Gardner, 1971). During the experiments, both B4 and B5 presynaptic cells $(100-150 \mu \mathrm{m}$ in diameter) and one postsynaptic neuron, either B3 or B6 (150-200 $\mu \mathrm{m}$ in diameter), were impaled with two glass microelectrodes $\left(3 \mathrm{M} \mathrm{KCl} ; \mathrm{Ag} / \mathrm{AgCl}_{2} ; 4-10 \mathrm{M} \Omega\right.$ for presynaptic neurons, $1.5-3 \mathrm{M} \Omega$ for postsynaptic neurons). ACh release was evoked by an action potential and monitored by measuring the amplitude of evoked postsynaptic response. Each evoked postsynaptic response was recorded as a membrane current $\left(I_{\mathrm{m}}\right)$ change (chloride dependent) using a conventional two-electrode voltage-clamp technique (Gene Clamp 500 or AxoClamp2B, Axon Instruments, Foster City, CA). The postsynaptic membrane current was filtered at a cutoff frequency of $250 \mathrm{~Hz}$ using an eight-pole low-pass bessel filter (902LPS, Frequency Device) before acquisition. The null potential for $\mathrm{Cl}^{-}$could be modified during the experiments because low-resistance $\mathrm{KCl}$-containing microelectrodes for clamping the postsynaptic neuron were used. To express the amplitude of the postsynaptic response as a value proportional to the amount of released $\mathrm{ACh}$, but independent of the driving force for $\mathrm{Cl}^{-}$, the amplitude of the postsynaptic response $I_{\mathrm{m}}$ was subsequently converted as an apparent membrane conductance $\left(G_{\mathrm{m}}\right)$ by taking into account the reversal potential $V_{\text {rev }}$ of the evoked response $\left(V_{\text {rev }}=E_{\mathrm{Cl}-}\right.$ for these responses) (Simonneau et al., 1980) according to the equation $G_{\mathrm{m}}=I_{\mathrm{m}} /\left(V_{\mathrm{h}}-V_{\text {rev }}\right)$. The reversal potential $\left(V_{\mathrm{rev}}\right)$ of the postsynaptic response was determined every $5 \mathrm{~min}$. To measure accurately the amplitude of the postsynaptic response, the holding potential $V_{\mathrm{hr}}$ was maintained $30 \mathrm{mV}$ above $V_{\text {rev }}$.

Stimulation of ACh release. During the experiments, each of the presynaptic neurons was depolarized over the threshold of action potential initiation by a square pulse of $50 \mathrm{msec}$ duration and the appropriate intensity. The frequency of stimulation was one stimulus every $40 \mathrm{sec}$, a condition that allowed stable recordings for at least $8 \mathrm{hr}$. Note that to avoid superpositioning the postsynaptic responses issuing from either B4 or B5 neurons, the stimulus protocols were alternated every $20 \mathrm{sec}$. When train or paired-pulse facilitation was studied, the stimulation protocol was changed as described below.

Paired-pulse and train facilitation. The term "facilitation" (Mallart and Martin, 1967) denotes the extent of increase in amplitude of a test response after a conditioning stimulus as compared with the conditioning response. To study paired-pulse facilitation, two brief depolarizing pulses of 5-20 msec (depending on the cell excitability) separated by a repolarizing phase of 15-200 msec were generated (SMP-311 pulse generator; Bio-Logic) and applied to the presynaptic neuron. In paired-pulse facilitation protocols, the interval between two presynaptic action potentials was calculated as the delay between the peaks of the paired action potentials. As described by Mallart and Martin (1967), facilitation $F$ was calculated from the equation $F=(i 2-i 1) / i 1$, with $i 1$ being the amplitude of the conditioning response and $i 2$ that of the test response.

Determination of i2. At the cholinergic synapses used in this study, the mean decay time of the evoked postsynaptic responses recorded at $22^{\circ} \mathrm{C}$ varies from 11 to $23 \mathrm{msec}$ depending on the postsynaptic cell and the preparation. Moreover, in $\sim 20 \%$ of the postsynaptic cells, the decay of the evoked postsynaptic responses was better fitted by a biexponential (with $\tau 1 \sim 9-15 \mathrm{msec}$ and $\tau 2 \sim 20-50 \mathrm{msec}$ ). It is possible that this corresponds to the two distinct time-opening durations reported for the postsynaptic chloride channels activated by ACh at these synapses (Simonneau et al., 1980; Fossier et al., 1983). Due to their long decay time, the postsynaptic responses evoked by a pair of stimuli overlapped partially at short interpulse intervals. Thus, the amplitude measured at the peak of response 2 was the sum of the actual amplitude of response 2 (i2) and the residual of response 1 . i 2 was calculated by deducing the extrapolated residual amplitude of response 1 at the time of the peak of response 2 and assuming a biexponential decay following the equation $i_{2}$ $\sim i_{\text {peak }} 2-i 1\left(\mathrm{a} \cdot \mathrm{e}^{-\Delta \mathrm{t} / \tau 1}+\mathrm{b} \cdot \mathrm{e}^{-\Delta \mathrm{t} / \tau 2}\right)$, where $\Delta t$ was the time interval between peak of response 2 and peak of response 1 (i.e., approximate interpulse time interval), $\tau 1$ and $\tau 2$ were the decay times, and $a$ and $b$ (with $a+b=1$ ) were the respective weights of the two exponentials. $\tau 1$, $\tau 2, a$, and $b$ were calculated in each experimental condition from several postsynaptic responses evoked by a single action potential. Note that when a monoexponential decay time was found, $b=0$.

Stimulation. Because of the high variability of paired-pulse facilitation at these synapses, determination of mean paired-pulse facilitation was calculated from at least 25 paired-pulse evoked responses for the same interpulse time interval. Because ACh release was not stable at higher stimulation frequencies, the delay between two subsequent paired pulses was maintained at $40 \mathrm{sec}$.

Calculation of facilitation during a train of stimuli. When required, trains of action potentials with an interpulse of $20 \mathrm{msec}$ were elicited (50 $\mathrm{Hz}$ train). Facilitation was determined only in short trains of eight action potentials. Calculation of the actual amplitude of the responses in the train was made via a procedure similar to that used for calculation of paired-pulse facilitation but extended to the residuals of the three preceding responses in the train. Facilitation of response $x$ was determined by comparing the amplitude of response $x$ with that of the initial response of the train: $F=\left(i_{\mathrm{x}}-i_{1}\right) / i_{1}$. Because repetitions of short stimulation trains also induced post-tetanic potentiation, these trains were elicited only every $35 \mathrm{~min}$, during control or after stabilization of Rab3-induced modification of release.

Post-tetanic potentiation. To initiate post-tetanic potentiation (PTP), three trains of action potentials $(1.5 \mathrm{sec}$ at $50 \mathrm{~Hz})$ were produced at $5 \mathrm{sec}$ intervals. Then, the stimulation rate was returned to control conditions. In each episode, the amplitude of PTP was determined as the mean of three subsequent postsynaptic responses measured at the peak of the potentiation; then it was normalized against the mean amplitude of the 10 postsynaptic responses preceding the tetanus.

Extracellular media. Dissected buccal ganglia were maintained at $22^{\circ} \mathrm{C}$ using a Peltier-plate system and superfused continuously $(10 \mathrm{ml} / \mathrm{hr})$ with a physiological medium containing $\mathrm{NaCl}(460 \mathrm{~mm}), \mathrm{KCl}(10 \mathrm{~mm}), \mathrm{CaCl}_{2}$ (33 mM), $\mathrm{MgCl}_{2}(50 \mathrm{~mm}), \mathrm{MgSO}_{4}(28 \mathrm{~mm})$, Tris Buffer (10 mM), $\mathrm{pH} 7.5$. This di-cation-rich medium, termed "control medium," was used to diminish spontaneous neuron firing activity and thus to minimize fluctuations in evoked ACh release. In this way, analysis of the kinetics of Rab3 action could be performed more easily. To change $\left[\mathrm{Ca}^{2+}\right]_{\mathrm{e}}$, the extracellular $\left[\mathrm{Ca}^{2+}\right] /\left[\mathrm{Mg}^{2+}\right]$ ratio was modified by changing the concentrations of $\mathrm{CaCl}_{2}$ and $\mathrm{MgCl}_{2}$ but not of $\mathrm{MgSO}_{4}$ to keep the sulfates unmodified. The $\left[\mathrm{Ca}^{2+}\right] /\left[\mathrm{Mg}^{2+}\right]$ ratio was defined as $Q=\left[\mathrm{CaCl}_{2}\right] /$ $\left(\left[\mathrm{MgCl}_{2}\right]+\left[\mathrm{MgSO}_{4}\right]\right)$. In the control physiological medium, $Q$ is $\sim 0.42$. Changes in the $\mathrm{Ca}^{2+} / \mathrm{Mg}^{2+}$ ratio were made to avoid (1) an osmotic pressure change that could affect neurotransmission (for review, see Van der Kloot and Molgó, 1994), (2) a change in the transmembrane $\mathrm{Cl}^{-}$ gradient because the recorded postsynaptic responses are $\mathrm{Cl}^{-}$dependent (Simonneau et al., 1980; Fossier et al., 1983), and (3) a change in the concentration of divalent cations because they can affect presynaptic excitability. The concentrations of $\left[\mathrm{CaCl}_{2}\right]$ and $\left[\mathrm{MgCl}_{2}\right]$ were calculated according to the following equations: $\left[\mathrm{CaCl}_{2}\right](\mathrm{mM})=Q \cdot(83+$ $\left.\left[\mathrm{MgSO}_{4}\right]\right) /(Q+1)$ and $\left[\mathrm{MgCl}_{2}\right](\mathrm{mM})=83-\left[\mathrm{CaCl}_{2}\right]$, with $Q$ being the $\left[\mathrm{Ca}^{2+}\right] /\left[\mathrm{Mg}^{2+}\right]$ ratio.

The $\left[\mathrm{Ca}^{2+}\right] /\left[\mathrm{Mg}^{2+}\right]$ ratios of 0.14 and 0.21 used for several experiments correspond to, respectively, $\mathrm{CaCl}_{2}=13.6 \mathrm{mM}, \mathrm{MgCl}_{2}=69.4 \mathrm{mM}$ and $\mathrm{CaCl}_{2}=19.3 \mathrm{~mm}$, and $\mathrm{MgCl}_{2}=63.7 \mathrm{~mm}$. Note that in Aplysia hemolymph, $\left[\mathrm{Ca}^{2+}\right] /\left[\mathrm{Mg}^{2+}\right]$ is $\sim 0.21$.

Intracellular $\mathrm{Ca}^{2+}$ changes. To modify the intracellular concentration of $\mathrm{Ca}^{2+}$ ions, EGTA was applied intraneuronally by pressure injection (see below). To avoid possible intracellular $\mathrm{pH}$ changes when $\mathrm{Ca}^{2+}$ binds to EGTA, the chelator was prepared in Tris-buffer, $\mathrm{pH} 7.4$, with an excess of Tris (stock solution containing EGTA $100 \mathrm{~mm}$, Tris $200 \mathrm{~mm}$, $\mathrm{pH}$ 7.4).

Intraneuronal injection procedure. Injection electrodes were pulled from glass tubing without a capillary $(0.5-1.5 \mathrm{M} \Omega)$. Then, the injection electrodes were coated with paraffin oil (Prolabo). This procedure was found to greatly facilitate the removal of the injection electrodes after intracellular injections were made. In addition, the injection electrodes contained a silver wire $(50 \mu \mathrm{m}$ in diameter, plunging into the solution to be injected) that allowed the electrophysiological monitoring of the impalement. They were filled with FC-77 (3M, Minneapolis, MN), an inert fluorocarbon compound that prevented desiccation of the sample to be contained in the tips of the injection electrodes. Before their intraneuronal injection, recombinant apRab3-Q80L or wild-type apRab3 proteins or EGTA-Tris solutions were mixed with a vital dye $[10 \% \mathrm{v} / \mathrm{v}$; fast green 

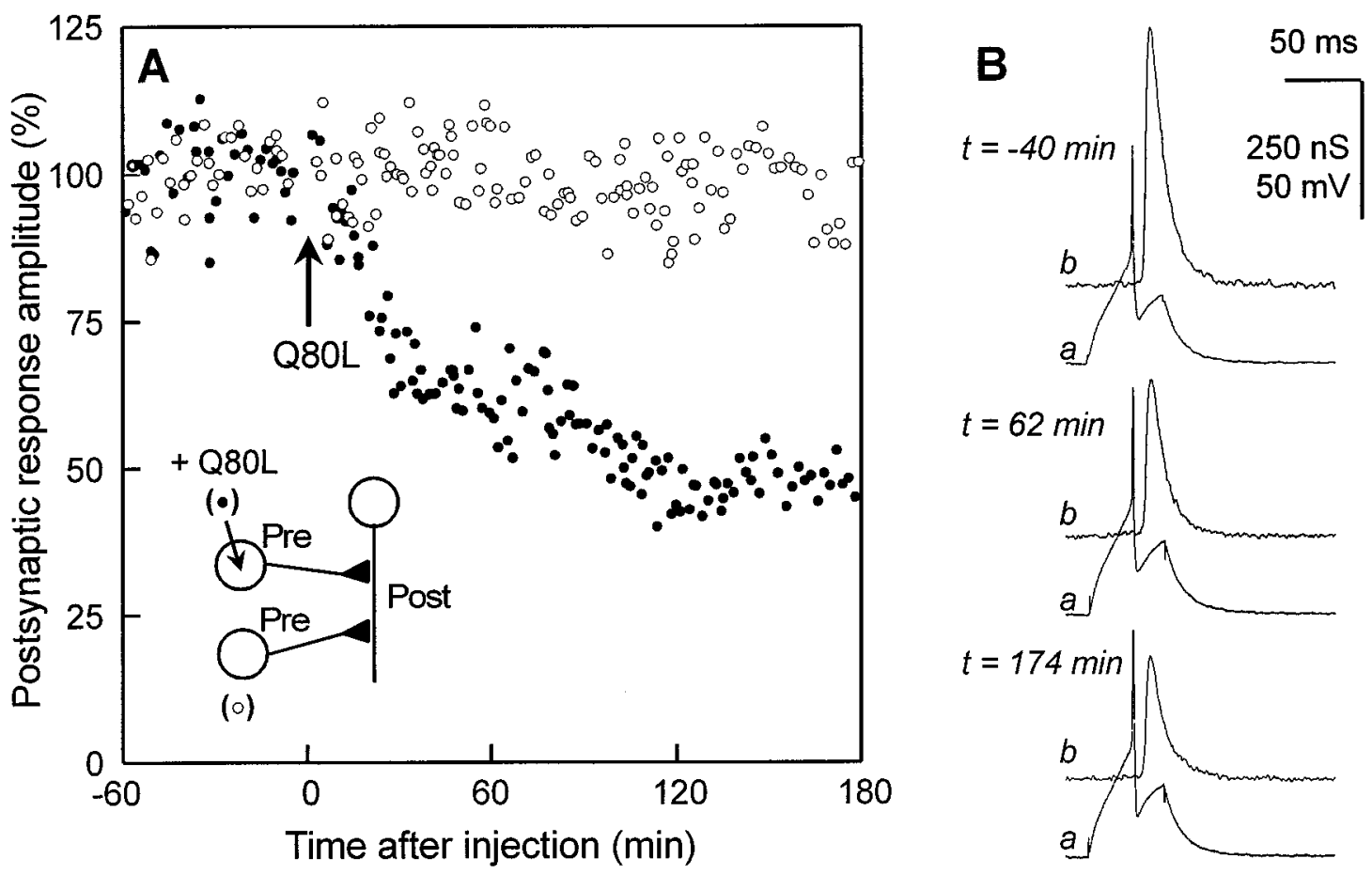

Figure 1. Inhibition of evoked acetylcholine release by recombinant GTPase-deficient Aplysia-Rab3. A, ACh release was evoked at identified synapses in the buccal ganglion of Aplysia californica. Postsynaptic response amplitude (\%) is plotted against time (after injection). After the control recording was made, recombinant Aplysia-Rab3 deficient in its GTPase activity (apRab3-Q80L, abbreviated as $Q 80 L$ in the figure) was pressure-injected into one of the two presynaptic cholinergic neurons (see inset for a schematic drawing of the neuronal connections). The final concentration of apRab3-Q80L was $\sim 0.3-0.5 \mu \mathrm{M}$ in the cell body; the other presynaptic neuron $(\bigcirc)$ was kept for internal control of release stability. $B$, Recordings of presynaptic action potentials $(a)$ and postsynaptic responses $(b)$, before and after injection of apRab3-Q80L. Note that amplitude of postsynaptic response is expressed as a change in postsynaptic conductance (nS). For further details see experimental procedures.

FCF (Sigma, St. Louis, MO), dissolved at near saturation in distilled water]. The tip of the injection microelectrode was filled by suction. When sequential injections were required, the first sample to be injected was mixed with $5 \%$ dye and the second with $20 \%$ dye. The samples were air pressure-injected using a picopump PV820 (WPI Ltd.) under visual and electrophysiological monitoring. The injected volume was in the range of $1 \%$ of that of the cell body. Hence, assuming a homogenous distribution of the injected material within the neuron arborization, the intracellular concentration reached after injection should be in the range of $1 \%$ of that into the injection micropipette. After injection, the injection micropipette was removed. After intracellular injection, only neurons with membrane potentials of -60 to $-45 \mathrm{mV}$ and with no alterations in the action potentials were considered. Note that intracellular administration of buffer solution used to prepare Rab3 protein produced no changes in transmitter release.

Other procedures. Construction, expression, and purification of the recombinant wild-type Aplysia Rab3 (wild-type apRab3) and GTPasedeficient Aplysia Rab3Q80L (apRab3-Q80L) were described previously (Johannes et al., 1996). When appropriate, data are presented as mean \pm SD. Statistical significance of the data were calculated by paired or unpaired $t$ tests.

\section{RESULTS}

\section{Decreases in intracellular $\left[\mathrm{Ca}^{2+}\right]$ potentiate the inhibition of $\mathrm{ACh}$ release induced by a constitutively GTP-bound Rab3}

It is generally believed that the GTP-binding protein Rab3 is in the "on" state when bound to GTP. Only the GTP-bound Rab3 is found associated with synaptic vesicles, and this Rab3 form interacts with downstream effectors. Therefore, in this study, we have used a recombinant GTPase-deficient Aplysia Rab3 to probe the function of GTP-bound Rab3 at identified synapses in Aplysia. This mutated recombinant protein was generated by a $Q>L$ substitution at position 80 in the sequence of Aplysia Rab3 and is referred to as apRab3-Q80L in the text and as Q80L in the figures. After the control level of evoked ACh release was determined, purified apRab3-Q80L was pressure-injected into one presynaptic cell. The concentration of apRab3-Q80L in the pipette was $30-80 \mu \mathrm{M}$, and the final intracellular concentration was estimated to be in the range of $\sim 0.3-0.8 \mu \mathrm{M}$. Simultaneously, transmitter release from another noninjected neuron was monitored to control the stability of release. In contrast to control neurons, evoked release from the apRab3-Q80L-injected neurons was progressively inhibited (a typical experiment is shown in Fig. 1). The mean inhibition, calculated $3 \mathrm{hr}$ after injection, was $35.8 \pm 14.9 \%(n=17)$, in agreement with our previous results using a recombinant human/aplysia Rab3 chimera (Johannes et al., 1996). Because of the low solubility of apRab3-Q80L, it was not possible to test whether higher concentrations of this mutated protein could further inhibit neuroexocytosis.

To determine whether the GTP-bound Rab3 inhibitory action is $\mathrm{Ca}^{2+}$ dependent, the intracellular free $\mathrm{Ca}^{2+}$ concentration was changed by injecting a $\mathrm{Ca}^{2+}$ chelator. EGTA was used because it is believed to be too slow to interfere with the transient $\mathrm{Ca}^{2+}$ influx involved in the triggering of neurotransmitter exocytosis (Alder et al., 1991). A mixture of EGTA-Tris buffer, $\mathrm{pH} 7.4$, was pressure-injected into presynaptic neurons. When the concentration in the pipette was increased $(10-100 \mathrm{~mm})$, the mean inhibition of evoked $\mathrm{ACh}$ release was also increased (Fig. $2 \mathrm{~A}$, and inset). At an intraneuronal concentration of EGTA estimated to be $\sim 200 \mu \mathrm{M}$, ACh release was depressed by $64.2 \pm 7.5 \%(n=7)$. In all experiments, the inhibitory effect of EGTA developed 

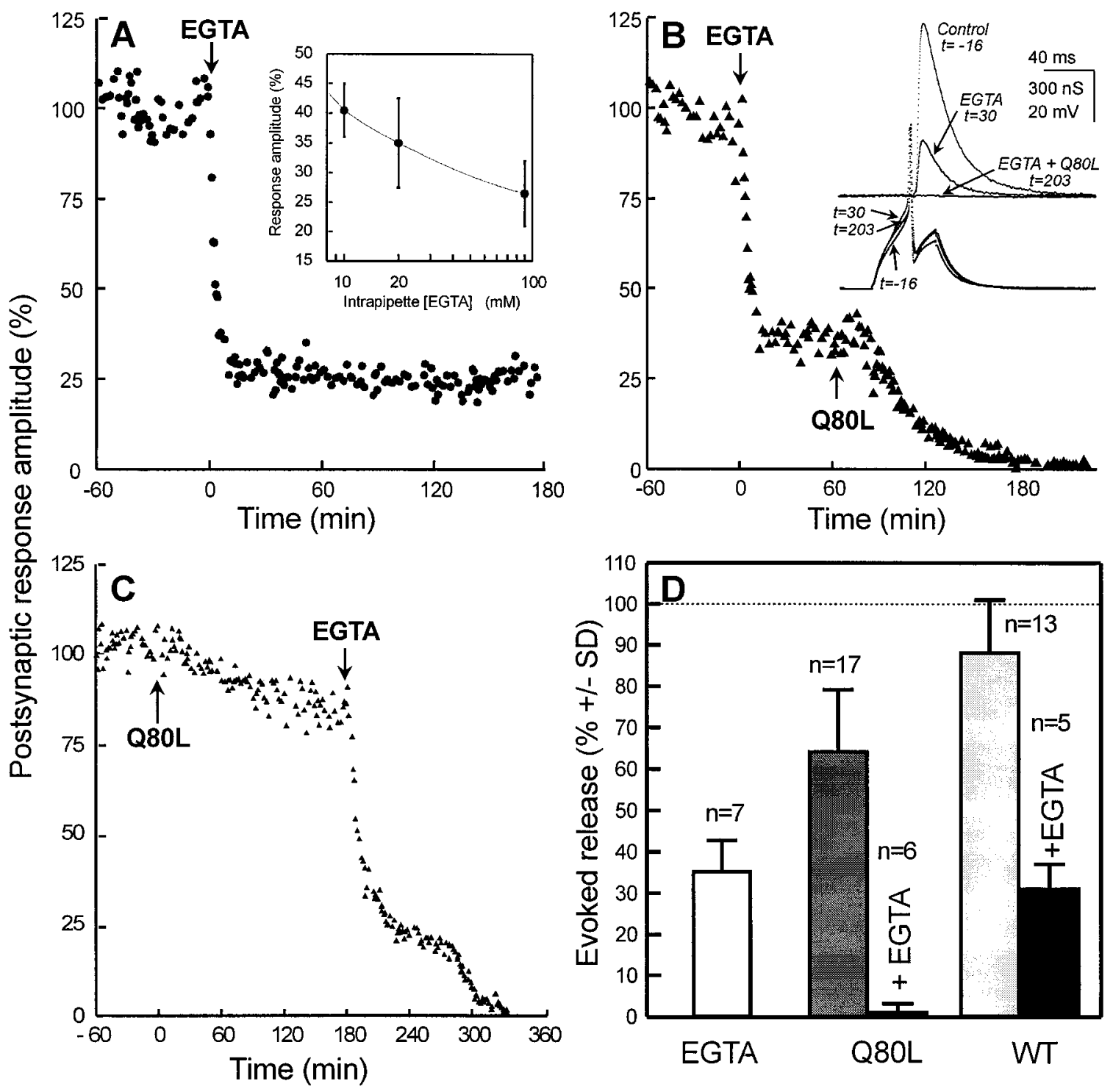

Figure 2. Intracellular removal of $\mathrm{Ca}^{2+}$ increases apRab3-Q80L efficacy. All experiments were similar to that described in Figure 1A. $A$, EGTA mixed with Tris buffer, pH 7.4 (20/40 mM respective concentrations in the injection pipette), was injected intracellularly (arrow; $\sim 1 \%$ of the cell body volume) giving rise to a final intrasomatic [EGTA] of $200 \mu \mathrm{M}$. Inset, Mean amplitude of postsynaptic responses as a function of intraneuronal [EGTA] ( \pm SD; $n=3-5$ ). B. A typical experiment of three is shown. EGTA was first injected (arrow) to give an intracellular concentration of $\sim 200 \mu \mathrm{M}$. After removal of the injection micropipette and stabilization of the inhibition of evoked release, a second micropipette containing apRab3-Q80L $(Q 80 L)$ was impaled. Then, apRab3-Q80L was pressure-injected (arrow; $\sim 0.3-0.5 \mu \mathrm{M}$ final in the soma). Inset, Typical recordings during the experiment. $C$, Similar experiment as in $B$ but in the reversed order. After EGTA injection, note the typical plateau (at $\sim 20 \%)$ at which postsynaptic responses transiently stabilized (it was seen in the 3 experiments performed). D, Comparison of the mean release $( \pm \mathrm{SD})$ observed $3 \mathrm{hr}$ after injection of EGTA-Tris alone $(\sim 200 / 400 \mu \mathrm{M}$ final intrasomatic concentration), apRab3-Q80L alone $(\sim 0.3-0.5 \mu \mathrm{M})$, or after sequential injection of both EGTA and apRab3-Q80L, wild-type apRab3 $(W T)$, alone $(\sim 0.3-0.5 \mu \mathrm{M})$ or combined with EGTA. Significance: for all comparisons, $p<0.001$, except WT alone (light gray bar) versus control, $p<0.01$, and EGTA alone (white bar) versus WT + EGTA (black bar), $p>0.2$.

rapidly (Fig. 2A). This inhibition remained stable for at least $6 \mathrm{hr}$ (Fig. $2 A$ ), even when the EGTA-containing micropipette was removed $1 \mathrm{hr}$ after the injection. Moreover, a subsequent injection of $\mathrm{CaCl}_{2}$ into EGTA-injected neurons allowed a transient recovery of $\mathrm{ACh}$ release (data not shown), and injection of Tris-buffer alone ( $\mathrm{pH} 7.4,>1 \mathrm{~mm})$ did not modify neurotransmission (data not shown) (also see Cornille et al., 1995). Hence, it is likely that the block of ACh release that follows EGTA intracellular application is caused by the lower $\left[\mathrm{Ca}^{2+}\right]_{i}$ that affects a $\mathrm{Ca}^{2+}$-dependent step of the release process; however, the sensitive $\operatorname{step}(\mathrm{s})$ remains undefined. At the cholinergic syn- apses used for this study, the diffusional distance between the opened $\mathrm{Ca}^{2+}$ channel(s) and the $\mathrm{Ca}^{2+}$ sensor involved in the triggering of the vesicle exocytosis is unknown. As also observed at mammalian central synapses (Borst and Sakmann, 1996), it is possible that several $\mathrm{Ca}^{2+}$ channels need to be open for each vesicle that undergoes exocytosis. Thus, we cannot exclude the possibility that part of the EGTA-induced inhibition of ACh release is attributable to the interception of a substantial amount of $\mathrm{Ca}^{2+}$ ions before they bind to the $\mathrm{Ca}^{2+}$-dependent trigger of exocytosis. On the other hand, the EGTA-induced blockade of transmitter release might be also attributable to its effect on one 
of the several $\mathrm{Ca}^{2+}$-dependent steps preceding the triggering of the secretory process (Bittner and Holz, 1992; Hsu et al., 1996).

Next, EGTA and apRab3-Q80L were sequentially injected. In the first set of three experiments, EGTA-Tris, pH 7.4, was pressure-injected to reach $\sim 200 \mu \mathrm{M}$ (final intracellular concentration); then, after removal of the injection electrode and stabilization of evoked release, apRab3-Q80L was pressure-injected into the same neuron. Under these conditions, a complete blockade of evoked $\mathrm{ACh}$ release was observed within $3 \mathrm{hr}$ after injection of the apRab3-Q80L (Fig. 2B-D). A similar observation was made when apRab3-Q80L was injected before EGTA (Fig. $2 C$ ). The kinetics of the apRab3-Q80L-induced blockade in neurons preinjected with EGTA was not strikingly different from that observed in control neurons (for instance, compare the onset of blockade in Fig. $2 B$ with that shown in Fig. $1 A$ ).

The combined effect of EGTA and apRab3-Q80L (35\% mean inhibition by apRab3-Q80L of the $25-40 \%$ remaining release after EGTA) had been expected to stabilize the evoked release at one-fourth to one-fifth of the initial value. Hence, the total blockade was unexpected and indicates that EGTA potentiated the inhibitory effect of apRab3-Q80L. A similar deduction was made from analyzing experiments in which apRab3-Q80L was injected before the intracellular application of EGTA. After the inhibition induced by apRab3-Q80L had stabilized (at $~ 20 \%$ in this experiment), EGTA injection resulted in a very fast onset of blockade followed by a period of nearly stable ACh release, as shown in Figure $2 C$ (a typical experiment from a series of three). The initial level of blockade reached $(\sim 25 \%$ of that before EGTA) was in the range of that expected by accumulation of the inhibition produced by apRab3-Q80L and EGTA alone. Then, a second inhibitory phase of blockade led to total inhibition. Most likely, this additional inhibition reflects the potentiation of the inhibitory action of apRab3-Q80L attributable to the chelation of intracellular $\mathrm{Ca}^{2+}$. To summarize, the total inhibition observed after sequential injection of EGTA and apRab3-Q80L suggests that the intracellular action of GTP-bound Rab3 is $\mathrm{Ca}^{2+}$ dependent.

\section{The weak inhibition of $\mathrm{ACh}$ release induced by injection of wild-type apRab3 does not appear to be affected by a decrease in intracellular $\left[\mathrm{Ca}^{2+}\right]$}

The effect of apRab3-Q80L on evoked ACh release might be attributable to either an increase in the levels of intraneuronal Rab3 or the replacement of a fraction of endogenous GTP-Rab3 (which cycles freely between "on" and "off" forms) by a modified protein that stays longer in the "on" state because of its reduced GTPase activity. To discriminate between these possibilities, we examined the intraneuronal actions of recombinant wild-type apRab3. The experiments were performed as described for apRab3-Q80L. When compared with apRab3-Q80L, recombinant wild-type apRab3 was found to be much less potent in altering neurotransmission. After its intraneuronal injection $(\sim 0.3 \mu \mathrm{M}$, final), ACh release was slightly diminished (to $88 \pm 13 \%, 3 \mathrm{hr}$ after injection; $n=13$ ) (Fig. $2 D$, light gray bar); in fact, no inhibition was detectable in 5 of 13 experiments, whereas in three experiments the extent of blockade was $>20 \%$. When a clear inhibition was detected, the kinetics of blockade appeared to be similar to that produced by apRab3-Q80L (data not shown). These results suggest that for most of the neurons studied, the endogenous concentration of Rab3 is not a crucial factor limiting exocytosis. Next, the ability of EGTA to modify the intracellular action of wild-type apRab3 was examined. In three experiments, wild-type apRab3 was injected first $(\sim 0.3 \mu \mathrm{M})$, and $3 \mathrm{hr}$ later, EGTA $(\sim 200 \mu \mathrm{M})$ was injected; in two experiments, EGTA was injected first, and after stabilization of the responses, wild-type apRab3 was injected. Three hours after the second injection, $\mathrm{ACh}$ release was found to be depressed to $31 \% \pm 6, n=5$, of its initial value (Fig. 2D). This value is comparable with that calculated by combining the inhibitory action of wild-type apRab3 (inhibition to 88\%) and that produced by EGTA (to 25-40\%). Hence, the inhibitory action of recombinant wild-type apRab3 does not appear to be particularly $\mathrm{Ca}^{2+}$ dependent.

The weak effect of recombinant wild-type apRab3 on ACh release suggests that the levels of endogenous Rab3 are not limiting in the secretory process, and that the effect of apRab3Q80L on neurotransmission is most likely attributable to its stabilization in the "on" state. Note that because endogenous levels of Rab3 are not limiting, the lack of apparent $\mathrm{Ca}^{2+}$ dependency of exogenous wild-type apRab3, as compared with that of apRab3-Q80L, does not preclude the possible $\mathrm{Ca}^{2+}$ dependency of endogenous Rab3 activity.

\section{Train facilitation is increased after inhibition of transmitter release by apRab3-Q80L}

The physiological significance of the $\mathrm{Ca}^{2+}$-dependent regulation of GTP-bound Rab3 effect was investigated. It was tempting to speculate that in contrast to intracellular $\mathrm{Ca}^{2+}$ buffering, any increase in $\left[\mathrm{Ca}^{2+}\right]_{i}$ should reduce the inhibition exerted by apRab3-Q80L on the exocytosis apparatus. Hence, we examined train and paired-pulse facilitation. These synaptic plasticity phenomena are known to be initiated by the transient augmentation of the residual $\left[\mathrm{Ca}^{2+}\right]_{\mathrm{i}}$ in the nerve terminal after repeated stimulations at short time intervals (Katz and Miledi, 1968; Swandulla et al., 1991; Kamiya and Zucker, 1994) (for review, see Zucker, 1989, 1996). A first indication that Rab3 action might be modulated by a rise in $\left[\mathrm{Ca}^{2+}\right]_{i}$ was obtained by comparing the facilitation of release observed during trains of repetitive action potentials in the absence or presence of excess GTP-bound Rab3 (i.e., after stabilization of the apRab3-Q80L-induced inhibition of ACh release). During the trains, facilitation was greatly increased after apRab3-Q80L injection. Figure $3 A$ shows a typical example from a series of five experiments that exhibited a clear augmentation of facilitation during a $50 \mathrm{~Hz}$ train of eight stimulations (by $27.2 \pm 8.6 \%$, at the eighth response; $n=5$ ). The potentiation was observed for the whole duration of the train (Fig. $3 B$ ), even when it was longer (tested up to $1.5 \mathrm{sec}$ duration) (Fig. $3 C$ is a typical example). Taken together, our experiments suggest that the negative clamp exerted by the GTP-bound form of Rab3 is reduced by an increase in $\left[\mathrm{Ca}^{2+}\right]_{\mathrm{i}}$. The kinetics of this calciumdependent modulation of Rab3 activity was assessed by examining paired-pulse facilitation.

\section{Paired-pulse facilitation is increased after injection of apRab3-Q80L}

At the cholinergic synapse of the buccal ganglion, paired-pulse facilitation was found to persist for more than $200 \mathrm{msec}$ after a conditioning pulse (a typical example is given in Fig. 4A). Although the experiments were performed at the same identified synapses of the buccal ganglion of Aplysia, the extent and dynamics of facilitation were found to vary greatly from animal to animal. For most of the synapses tested ( 23 of 43 neurons), paired stimuli induced a facilitation that peaked at a $20-40 \mathrm{msec}$ interpulse interval (Fig. 4A). By contrast, at several synapses (13 of 43) a paired-pulse facilitation with a negative value was detected. For 

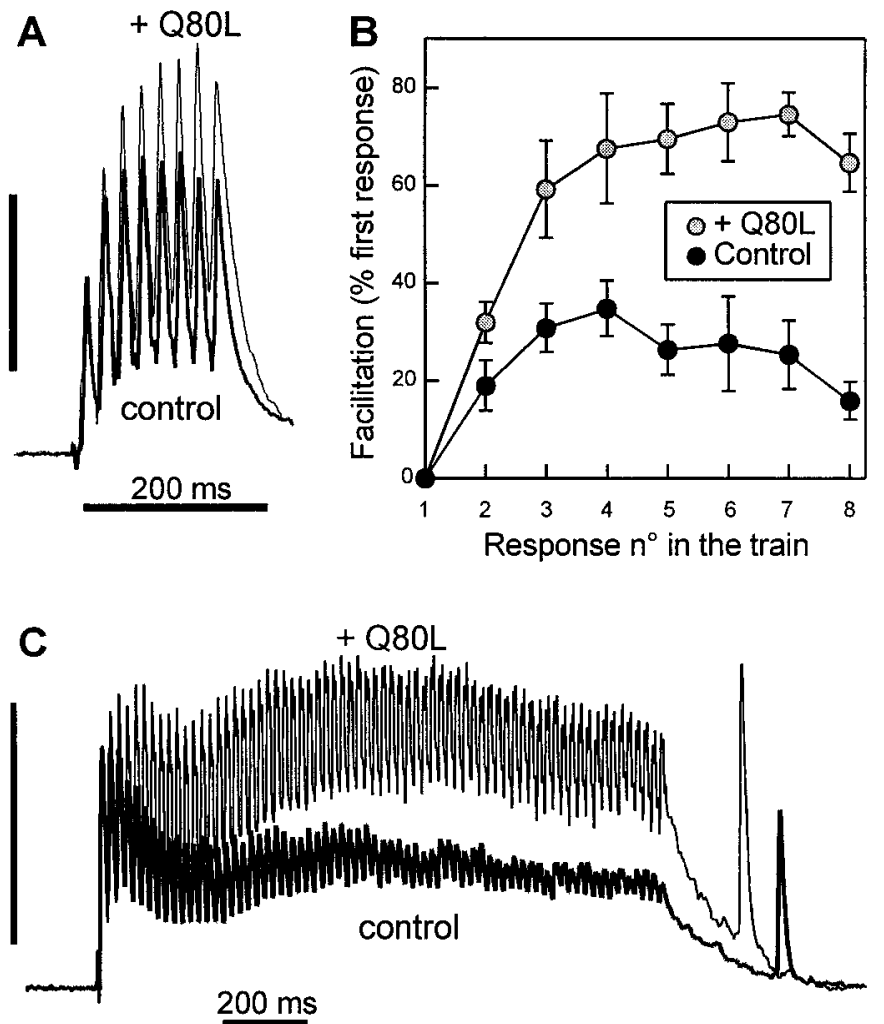

Figure 3. Evoked ACh release under repetitive stimulation is potentiated after injection of apRab3-Q80L. $A, B$, Trains of eight action potentials at $50 \mathrm{~Hz}$ were elicited both in control conditions (control) and after stabilization of the inhibition induced by apRab3-Q80L $(+Q 80 L)$. In this experiment, the inhibition induced by apRab3-Q80L was $51 \%, 3 \mathrm{hr}$ after injection. $A$ shows the superposition of two postsynaptic recordings made in these two conditions; they were normalized against the amplitude of the first response in the train. Recording in control condition is denoted by the thick line. Vertical calibration (100\% of first response in the train): $485 \mathrm{nS}$ (control, before injection of apRab3-Q80L) and $250 \mathrm{nS}$ (after injection of apRab3-Q80L and stabilization of the inhibition). B, Facilitation was determined for each of the eight stimulations in the train. In this typical experiment from a series of five, the plot shows the averaged facilitation values (mean $\pm \mathrm{SD} ; p<0.001$ ) determined for six trains in the absence or the presence of apRab3-Q80L. $C$, Effect of apRab3-Q80L on the facilitation observed during a $1.5 \mathrm{sec}$ train of action potentials at 50 $\mathrm{Hz}$. Same presentation as in $A$. In this experiment, the mean inhibition produced by apRab3-Q80L was $42 \%$. Vertical calibration (100\% of first response in the train): $1020 \mathrm{nS}$ (before injection) and $620 \mathrm{nS}$ (after injection).

7 of the 43 cells studied, no net facilitation could be detected (facilitation ranging from -3 to $+3 \%$ at a $40 \mathrm{msec}$ interpulse interval). To investigate the effect of apRab3-Q80L on pairedpulse facilitation, these experiments were performed in control conditions and after injection of apRab3-Q80L. In the eight experiments performed, paired-pulse facilitation was significantly higher in the presence of the mutated protein (Fig. 4A,B). When a negative facilitation was seen during the control period (Fig. $4 B$, cells 6-8), it was reduced after injection of apRab3-Q80L. Importantly, the augmentation of facilitation was higher at the peak of facilitation and marginal for the longest interpulse time interval (Fig. 4A). Therefore, the apRab3-Q80L-induced increase in facilitation parallels the changes in $\left[\mathrm{Ca}^{2+}\right]_{\mathrm{i}}$. The increase in paired-pulse facilitation induced by apRab3-Q80L was consistent with the potentiation of release detected during a train of action potentials (Fig. 3) and again suggests that the negative effect of
apRab3-Q80L on evoked release is depressed during a transient increase in $\left[\mathrm{Ca}^{2+}\right]_{i}$.

Because the "residual $\mathrm{Ca}^{2+}$ hypothesis" (Katz and Miledi, 1968; Kamiya and Zucker, 1994) has been debated (Blundon et al., 1993), we examined experimental situations in which the $\mathrm{Ca}^{2+}$ dependency of both paired-pulse facilitation and apRab3Q80L action on facilitation could be addressed simultaneously. $\left[\mathrm{Ca}^{2+}\right]_{\mathrm{e}}$ was lowered by modifying the extracellular $\left[\mathrm{Ca}^{2+}\right] /$ $\left[\mathrm{Mg}^{2+}\right]$ ratio. As observed at other synapses (for review, see Zucker, 1989, 1996; Van der Kloot and Molgó, 1994), evoked $\mathrm{ACh}$ release was found to diminish (data not shown) and pairedpulse facilitation to increase when $\left[\mathrm{Ca}^{2+}\right]_{\mathrm{e}}$ was lowered (Fig. $5 \mathrm{~A}$, black bars). Although the magnitude of the inhibition induced by apRab3-Q80L was not affected significantly by lowering $\left[\mathrm{Ca}^{2+}\right]_{\mathrm{e}}$ (data not shown), its ability to increase facilitation was found to be diminished (Fig. $5 A$ ). At the lowest $\left[\mathrm{Ca}^{2+}\right] /\left[\mathrm{Mg}^{2+}\right]$ ratio tested (0.14), no significant effect was detected (Fig. 5A) $(p>0.05)$. The significance of this observation could be ascertained because we were able to study paired-pulse facilitation subsequently in low $\mathrm{Ca}^{2+}$ medium $\left(\left[\mathrm{Ca}^{2+}\right] /\left[\mathrm{Mg}^{2+}\right]\right.$ ratio of 0.14$)$ and control medium $\left(\left[\mathrm{Ca}^{2+}\right] /\left[\mathrm{Mg}^{2+}\right]\right.$ ratio of 0.42$)$, both before and after apRab3Q80L injection, for three neurons. As shown in Figure $5 B$, the increment in facilitation measured in low $\mathrm{Ca}^{2+}$ medium was marginal as compared with that observed for the same neurons in control medium. There are two possible interpretations of this observation. Either the high magnitude of paired-pulse facilitation at low $\left[\mathrm{Ca}^{2+}\right]_{\mathrm{e}}$ masks the potentiating effect of apRab3-Q80L observed in control medium or facilitation had already reached a maximal value that could not be increased further by injecting apRab3-Q80L.

According to the residual $\left[\mathrm{Ca}^{2+}\right]$ hypothesis, paired-pulse facilitation depends on the spatial and time overlap of $\mathrm{Ca}^{2+}$ microdomains that build up near calcium channels. Therefore, we used $\mathrm{Cd}^{2+}$ ions that block indiscriminately all kinds of voltagedependent $\mathrm{Ca}^{2+}$ channels (for review, see Van der Kloot and Molgó, 1994) to reduce the number of sites of $\mathrm{Ca}^{2+}$ influx. Superfusion of the buccal ganglion with a physiological medium $\left(\left[\mathrm{Ca}^{2+}\right] /\left[\mathrm{Mg}^{2+}\right]\right.$ ratio of 0.42$)$ containing $200 \mu \mathrm{M} \mathrm{CdCl}$ reduced ACh release to nearly half $(54 \pm 12 \% ; n=6)$ (see also Figure $6 A$, closed and open symbols). This blockade appeared to be caused mainly by an inhibition of $\mathrm{Ca}^{2+}$ entry because $\mathrm{ACh}$ release could be fully restored after washing (Fig. $6 A$, open symbols). In addition, intracellular injection of $\mathrm{CdCl}_{2}(>100 \mu \mathrm{M}$, final intrasomatic concentration) did not modify evoked neurotransmission (not shown). After stabilization of the $\mathrm{CdCl}_{2}$-induced blockade, paired-pulse facilitation appeared to be nearly abolished $(-4.8 \%$ $\pm 9.8 ; n=6 ; 40 \mathrm{msec}$ interpulse interval). This result is in complete agreement with similar observations at the vertebrate neuromuscular junction (for review, see Van der Kloot and Molgó, 1994). When apRab3-Q80L was injected after stabilization of the $\mathrm{Cd}^{2+}$-induced inhibition of $\mathrm{ACh}$ release, release was inhibited by an extent that was similar in magnitude to that observed in the absence of $\mathrm{Cd}^{2+}(46 \pm 9 \% ; n=3$ to compare with $36 \% ; n=17 ; p>0.05)$; see for example condition 3 in Figure $6 A$. However, more importantly, paired-pulse facilitation was unaffected when apRab3-Q80L was injected in the presence of $\mathrm{CdCl}_{2}$. A typical experiment of three is shown in Figure $6 B$; compare bars in conditions 2 and 3. After $\mathrm{Cd}^{2+}$ ions were washed out, evoked $\mathrm{ACh}$ release could be recovered from the $\mathrm{Cd}^{2+}$ block, and a clear increase in paired-pulse facilitation could be induced by apRab3-Q80L (Fig. 6B; bar in condition 4; see top recording in $C$ ). These experiments showed that minimizing the 

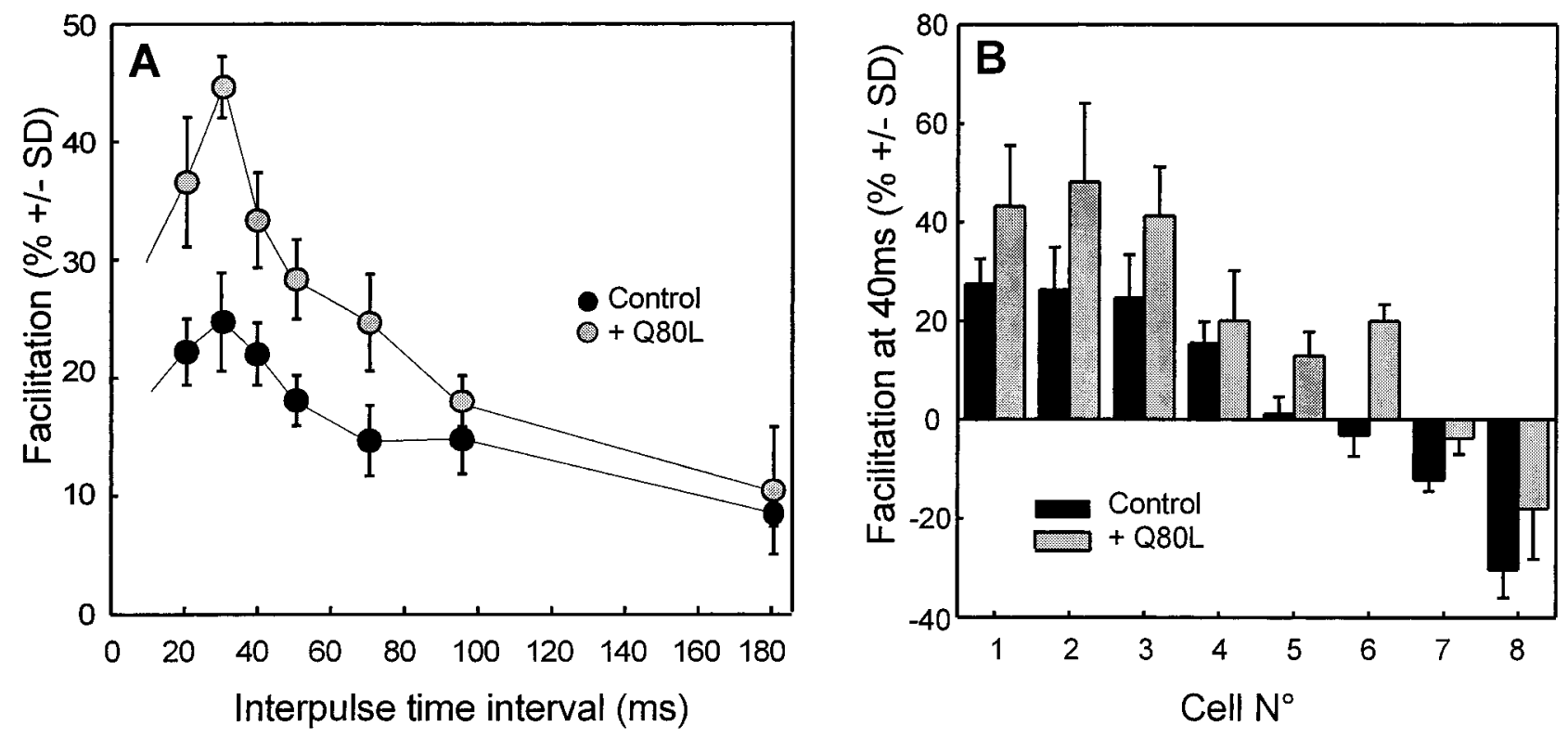

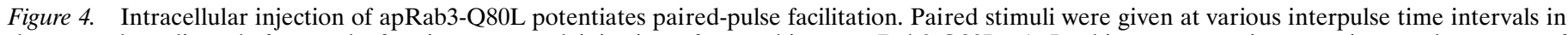

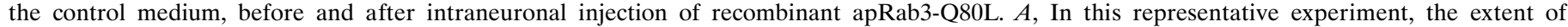

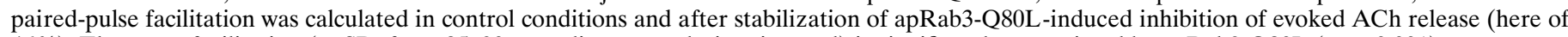

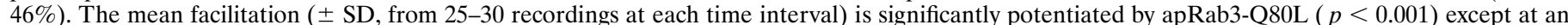

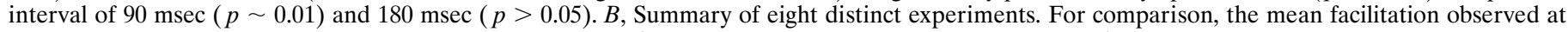

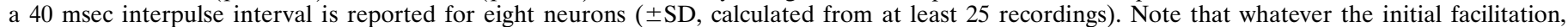
positive or negative, apRab3-Q80L application was followed by an increased facilitation. For all cells, $p<0.001$.

changes in residual $\left[\mathrm{Ca}^{2+}\right]_{\mathrm{i}}$ prevents apRab3-Q80L from increasing paired-pulse facilitation. Therefore, the action of GTP-bound Rab3 on facilitation is functionally linked to the $\mathrm{Ca}^{2+}$ dependency of facilitation.

\section{Post-tetanic potentiation is not modified after injection of apRab3-Q80L}

Because a rise in $\left[\mathrm{Ca}^{2+}\right]_{\mathrm{i}}$ underlies different forms of synaptic plasticity (Zucker, 1989, 1996), we investigated the possibility that injection of apRab3-Q80L might also alter post-tetanic potentiation (PTP). This latter is initiated by an increase in residual $\left[\mathrm{Ca}^{2+}\right]_{\mathrm{i}}$ that accumulates during tetanic stimulation (Kretz et al., 1982; Swandulla et al., 1991; Kamiya and Zucker, 1994; Bao et al., 1997). At the cholinergic synapse of the buccal ganglion, PTP was easily and reproducibly initiated by three trains of action potentials at $50 \mathrm{~Hz}$ for $1.5 \mathrm{sec}$ each (Fig. 7). During PTP, the evoked $\mathrm{ACh}$ release was enhanced by $33.5 \pm 5.2 \%$ in control conditions. PTP lasted $>30$ min (mean of eight PTPs measured in control period; three neurons). It is likely that PTP duration largely exceeds the time required by the nerve terminals to buffer $\left[\mathrm{Ca}^{2+}\right]_{\mathrm{i}}$ to its resting level. Interestingly, although apRab3-Q80L clearly increased facilitation during the conditioning trains (Fig. $4 C$ ), neither the amplitude nor time course of PTP was affected (Fig. 7). After apRab3-Q80L injection, the mean increase of ACh release during PTP was $39 \pm 7.2 \%$ (mean of six PTPs recorded in three neurons at least $2 \mathrm{hr}$ after injection of the GTPasedeficient apRab3). Similarly, the PTP at hippocampal slices from Rab3A-deficient mice are unaltered (Geppert et al., 1994; Castillo et al., 1997). The absence of PTP modification pinpoints the possibility that the modulation of GTP-Rab3 action by $\mathrm{Ca}^{2+}$ does not persist long after $\left[\mathrm{Ca}^{2+}\right]_{\mathrm{i}}$ has returned to a normal level.

\section{DISCUSSION}

\section{The GDP/GTP cycling of Rab3A is rate-limiting for calcium-dependent exocytosis}

A recombinant GTPase-deficient Rab3 protein was introduced intracellularly to gain insight into the functional role of GTPbound Rab3 in neuroexocytosis. According to our previous work (Johannes et al., 1996), apRab3-Q80L inhibits $\mathrm{Ca}^{2+}$-dependent evoked release; wild-type apRab3 is much less potent. These findings are in agreement with (1) the inhibition of the secretion induced by overexpression or injection of wild-type or GTPasedeficient Rab3A in chromaffin cells and PC12 cells (Holz et al., 1994; Johannes et al., 1994; Weber et al., 1996) or insulinsecreting cells (Regazzi et al., 1996) and (2) the increased secretory activity that follows suppression of Rab3A via an antisense strategy (Johannes et al., 1994) or by the knock-out of Rab3A gene in mice (Geppert et al., 1997). Taken together, these results suggest that Aplysia-Rab3 is a functional homolog of mammalian Rab3A.

The intracellular actions of apRab3-Q80L and wild-type apRab3 differ in potency. The weak effect of exogenous apRab3 on neurotransmission suggests that the levels of endogenous apRab3 were not limiting for exocytosis in most of the neurons studied. The stronger action of apRab3-Q80L as compared with wild-type apRab3 may be easily explained by the fact that apRab3-Q80L remains longer than the wild-type protein under the GTP-bound form because of its reduced GTPase activity. Therefore, the inhibitory effect of apRab3-Q80L on ACh release demonstrates that the GTP/GDP cycling of Rab3 is functionally linked to the exocytotic process. Whether this inhibitory effect of apRab3-Q80L highlights a negative modulatory action of endogenous GTP-bound Rab3 or indicates that GTP hydrolysis by Rab3, per se, constitutes the positive signal required for exocy- 


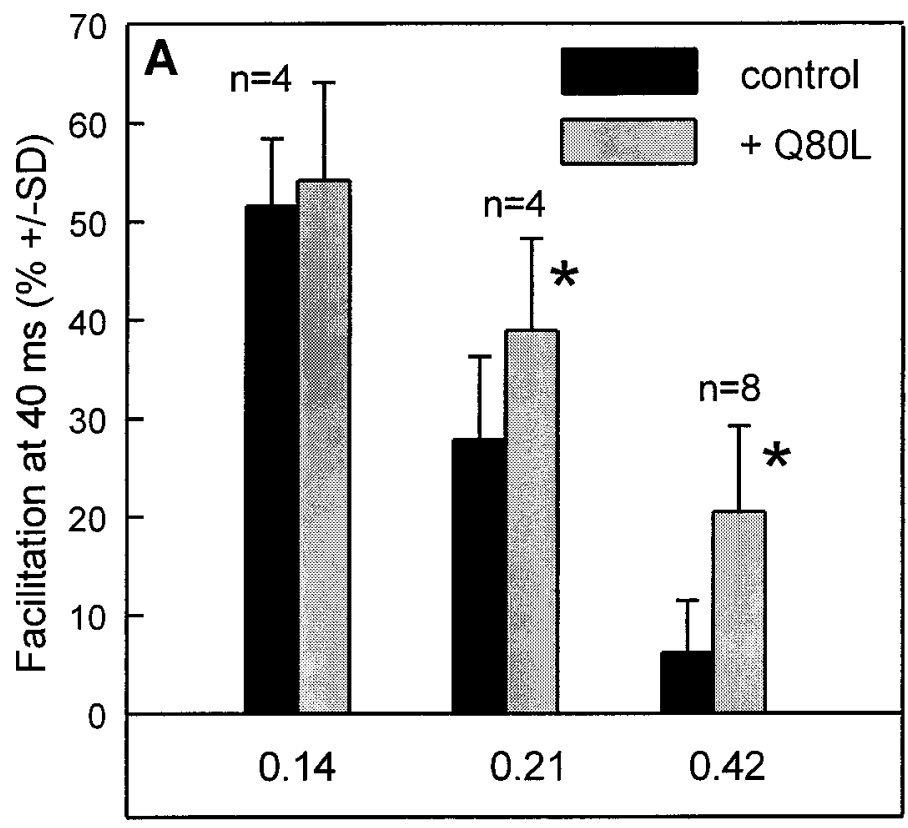

Extracellular [Ca]/[Mg] ratio

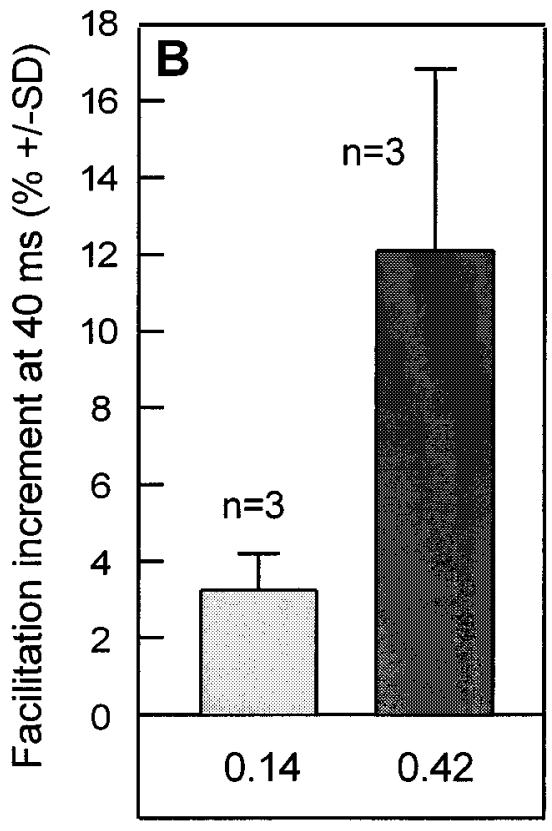

$[\mathrm{Ca}] /[\mathrm{Mg}]$ ratio

Figure 5. $\mathrm{Ca}^{2+}$ dependency of the effect of apRab3-Q80L on paired-pulse facilitation. $A$, In separate experiments, neurotransmitter release was evoked in the presence of a physiological medium with $\left[\mathrm{Ca}^{2+}\right] /\left[\mathrm{Mg}^{2+}\right]$ ratios of $0.14,0.21$, or 0.42 to change extracellular $\left[\mathrm{Ca}^{2+}\right]$. When referred to the release measured at a $0.42\left[\mathrm{Ca}^{2+}\right] /\left[\mathrm{Mg}^{2+}\right]$ ratio, ACh release was depressed to $72 \%( \pm 7 ; n=4)$ at $0.21\left[\mathrm{Ca}^{2+}\right] /\left[\mathrm{Mg}^{2+}\right]$ ratio and to $35 \%( \pm 8 ; n=4)$ at 0.14 $\left[\mathrm{Ca}^{2+}\right] /\left[\mathrm{Mg}^{2+}\right]$ ratio. Paired-pulse facilitation was determined (as described in Fig. 4) at these different ionic conditions (black bars). Then apRab3-Q80L was injected into the neurons, and after stabilization of the inhibition induced by apRab3-Q80L, paired-pulse facilitation was determined ( gray bars). Note that the paired-pulse facilitation values are reported for an interpulse interval of $40 \mathrm{msec}$. Asterisk denotes that $p<0.001$. At $\left[\mathrm{Ca}^{2+}\right] /\left[\mathrm{Mg}^{2+}\right]$ ratio $=$ $0.14, p>0.05$. B. Similar experiment as in $A$, except paired-pulse facilitation was determined for each neuron at the unique 40 msec interval in control medium $\left(\left[\mathrm{Ca}^{2+}\right] /\left[\mathrm{Mg}^{2+}\right]\right.$ ratio of 0.42$)$ and then in low $\mathrm{Ca}^{2+}$ medium $\left(\left[\mathrm{Ca}^{2+}\right] /\left[\mathrm{Mg}^{2+}\right]\right.$ ratio of 0.14$)$. Similar measurements were made after stabilization of the inhibition induced by apRab3-Q80L. At each $\left[\mathrm{Ca}^{2+}\right] /\left[\mathrm{Mg}^{2+}\right]$ ratio, results are expressed as the mean difference between the facilitation observed before and after injection of the mutated Rab3 protein; $p<0.001$.

tosis to proceed further is still an open question. GTP hydrolysis by Rab5 is not necessary for homotypic fusion of early endosomes (Rybin et al., 1996). Moreover, in rat intermediate pituitary cells, a GTPase-deficient Rab3A protein increases the secretory activity (M. Rupnik, L. Johannes, F. Nothias, L. KocmurBobanovic, R. Zorec, P. Vernier, and F. Darchen, unpublished observations). Thus, in these cells GTP hydrolysis by Rab3A is not essential for exocytosis. The GTPase activity of Rab3 seems likely to act as a timer for synaptic vesicle exocytosis as proposed for Rab5 in the endocytic process (Rybin et al., 1996). Hence, apRab3-Q80L would inhibit exocytosis by slowing the synaptic vesicle cycle, probably because it delays the release of downstream effectors such as Rabphilin and Rim that interact specifically with GTP-bound Rab3.

The steps regulated by GTP-bound Rab3 are still unclear. Consistent with the identification of several effectors/acceptors for Rab3, Rab3 seems to intervene at different stages in the exocytosis of synaptic vesicles (for review, see Bean and Scheller, 1997). Examination of Caenorhabditis elegans Rab3 mutant synapses suggests that Rab3 may regulate the recruitment of vesicles to the active zone or sequestration of vesicles near the release site (Nonet et al., 1997). By analogy with Rab5 action (Rybin et al., 1996), Rab3 may stabilize the docking-fusion complex. We have proposed that Rab3 acts after the SNARE complex formation (i.e., after the docking of synaptic vesicles) (Johannes et al., 1996). Hence, Rab3 would contribute to synaptic vesicle priming. Moreover, Rab3A may have a very late action on exocytosis, after the
$\mathrm{Ca}^{2+}$-dependent step that determines release probability (Geppert et al., 1997).

\section{Negative regulation of exocytosis by GTP-bound Rab3 is $\mathrm{Ca}^{2+}$ dependent}

The regulation of neurotransmitter release by the GTP-bound form of Rab3 depends in some way on $\left[\mathrm{Ca}^{2+}\right]_{i}$. Indeed, the inhibitory action of apRab3-Q80L on neuroexocytosis was found to be strongly potentiated when $\left[\mathrm{Ca}^{2+}\right]_{\mathrm{i}}$ was lowered (Fig. 2). Moreover, an increase in two $\mathrm{Ca}^{2+}$-dependent forms of shortterm plasticity, paired-pulse and train facilitation, was observed in the presence of apRab3-Q80L (Figs. 3, 4). A likely interpretation is that the inhibitory action of apRab3-Q80L, and most likely of GTP-Rab3, on exocytosis is depressed when $\left[\mathrm{Ca}^{2+}\right]_{\mathrm{i}}$ is enhanced. Note, however, that if apRab3-Q80L inhibits the release process by decreasing only the release probability $p$, in paired stimulations, the conditioning stimulus would recruit a smaller fraction of releasable vesicles and thus the test stimulus would act on a larger number of vesicles, leading to an increased paired-pulse facilitation. This possibility seems unlikely because (1) it could not easily account for the increased facilitation observed during long trains of stimulations in which the absolute magnitude of the responses is very similar in control and apRab3-Q80L injected neurons; (2) at hippocampal synapses of Rab3A-deficient mice, $p$ was not modified (Geppert et al., 1997); and (3) the action of Rab3 before vesicle docking deduced from studies on C.elegans (Nonet et al., 1997) suggests that a part of Rab3 function is to regulate $n$, the 


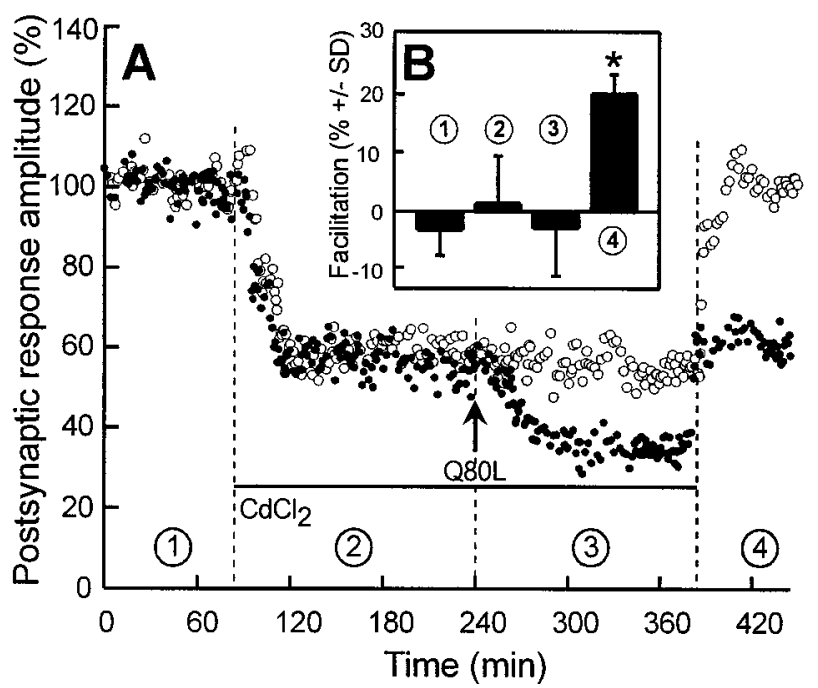

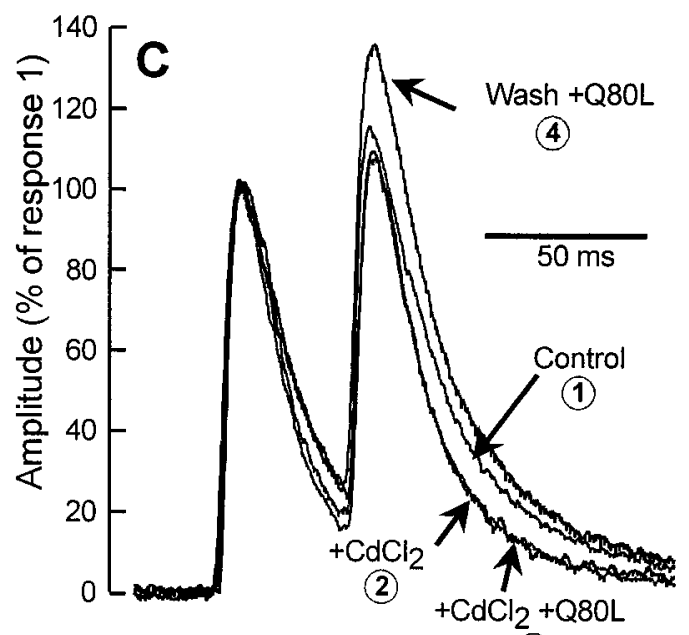

(3)

Figure 6. Effect of $\mathrm{CdCl}_{2}$ on paired-pulse facilitation before and after injection of apRab3-Q80L. $A$, In this typical experiment, neurotransmitter release from two neurons was followed in the presence of control medium (condition 1), in presence of $200 \mu \mathrm{M} \mathrm{CdCl}_{2}$ (denoted by the horizontal bar in conditions 2 and 3), and after washing out $\mathrm{CdCl}_{2}$ (condition 4). In addition, one neuron (-) was injected with apRab3-Q80L (arrow, Q80L; conditions 3 and 4). $B$, For the neuron identified by (i.e., the one injected by apRab3-Q80L), paired-pulse facilitation (mean \pm SD) was determined at a 40 msec interpulse interval in the four experimental conditions described in $A$. Asterisk denotes $p<0.001$ when the amplitude of facilitation is compared with any other condition. $C$, Typical recordings of paired postsynaptic responses recorded in the four experimental conditions described in $A$. For comparison, postsynaptic responses were normalized against the amplitude of the first response in the pair. Note that decay times of postsynaptic responses were shorter in $\mathrm{CdCl}_{2}$; this was taken into account for determining paired-pulse facilitation (see Materials and Methods).

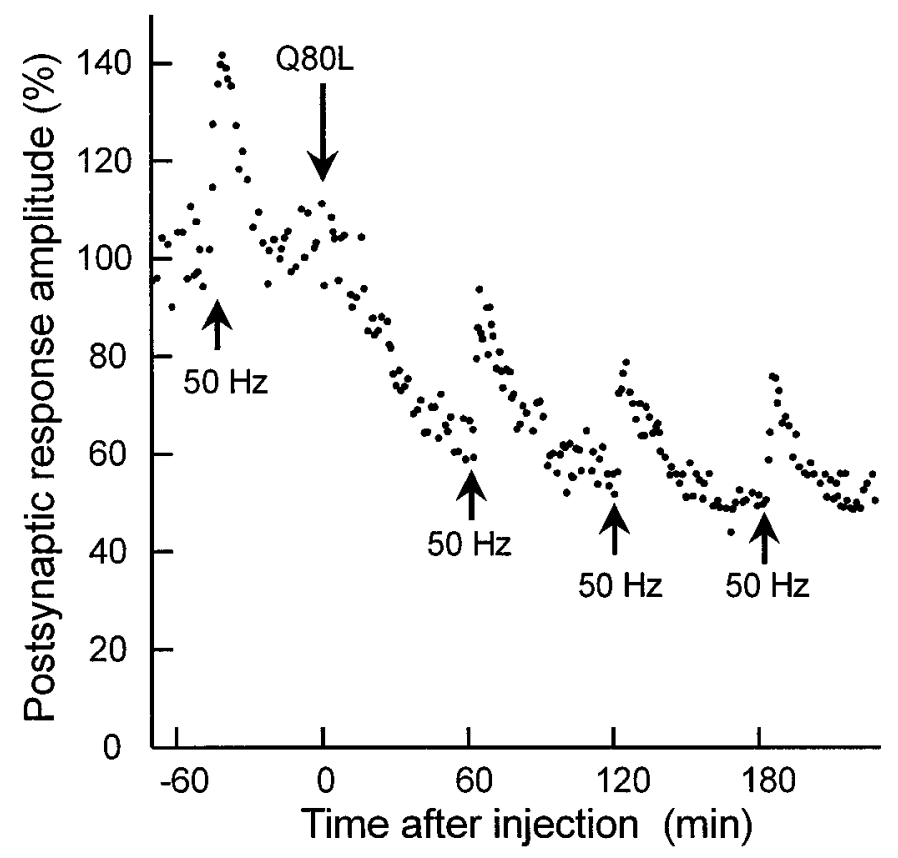

Figure 7. Post-tetanic potentiation is not affected by apRab3-Q80L. This experiment was similar to that described in Figure 1, and in addition, during control period or after injection of apRab3-Q80L, post-tetanic potentiation (PTP) was elicited (arrows) (see Materials and Methods). For simplification, only one PTP is reported during the control period. The magnitude of PTP was not significantly different before and after injection of apRab3-Q80L.

number of releasable vesicles. Moreover, when transient changes in $\left[\mathrm{Ca}^{2+}\right]_{\mathrm{i}}$ were minimized by extracellular application of $200 \mu \mathrm{M}$ $\mathrm{Cd}^{2+}$, the increase in paired-pulse facilitation induced by apRab3-Q80L was abolished (Fig. 6B), whereas apRab3-Q80L was still able to inhibit ACh release (Fig. 6A).
The on-off kinetics of GTP-Rab3 modulation by $\mathrm{Ca}^{2+}$ appears to be very fast: a clear effect of apRab3-Q80L on facilitation could be detected for a stimulus interval of $20 \mathrm{msec}$. This effect persisted during the whole duration of trains of stimuli at $50 \mathrm{~Hz}$ (Fig. 3C), but PTP was unaffected. Hence, the timing of the modulation of GTP-Rab3 activity seems to parallel that of the $\mathrm{Ca}^{2+}$ transient. In agreement with our observations of a $\mathrm{Ca}^{2+}$ dependency of Rab3 action, intracellular application of antisense oligonucleotides directed against Rab3A mRNA into bovine chromaffin cells leads to increased secretory activity that is magnified at low $\left[\mathrm{Ca}^{2+}\right]_{\mathrm{i}}$ (Johannes et al., 1994). To summarize, GTP-Rab3 acts as a $\mathrm{Ca}^{2+}$-dependent brake for the vesicle exocytosis process, and a physiological way to remove this effect might be to increase $\left[\mathrm{Ca}^{2+}\right]_{\mathrm{i}}$.

Until now, there has been no indication suggesting that the intrinsic activity of Rab3 might be $\mathrm{Ca}^{2+}$ dependent. The $\mathrm{Ca}^{2+}$ dependency of GTP-Rab3 action might be accounted for by two mechanisms. First, $\mathrm{Ca}^{2+}$ might affect the functional cycle of Rab3, for instance, by modulating the activity of the specific Rab3-GTPase-activating protein (Fukui et al., 1997) or by acting on calmodulin, because it was reported recently that $\mathrm{Ca}^{2+}$ / calmodulin causes Rab3A to dissociate from synaptic membranes (Park et al., 1997). Second, GTP-bound Rab3 action on the secretory process may be modulated as a function of $\left[\mathrm{Ca}^{2+}\right]_{\mathrm{i}}$ through the action of $\mathrm{Ca}^{2+}$-binding effectors that act downstream of GTP-Rab3. Two possible effectors, Rabphilin and Rim, interact with Rab3 as a function of its binding to GTP, and both of them have $\mathrm{Ca}^{2+}$ /phospholipid binding domains ( $\mathrm{C} 2$ domains) that might be responsible for the observed $\mathrm{Ca}^{2+}$-dependent modulation of the GTP-Rab3 effect (Shirataki et al., 1992; McKiernan et al., 1993; Wang et al., 1997). In addition, the binding of Rabphilin to phospholipids occurs in the presence of micromolar concentrations of $\mathrm{Ca}^{2+}$ (Yamaguchi et al., 1993). These values are in agreement with the apparent $\mathrm{Ca}^{2+}$ affinities of the priming step of exocytosis (Bittner and Holz, 1992) and that of the $\mathrm{Ca}^{2+}$ 
sensors involved in several synaptic plasticity phenomena. Indeed, it has been reported previously that facilitation implicates $\mathrm{Ca}^{2+}$ targets that have higher $\mathrm{Ca}^{2+}$ affinities than the $\mathrm{Ca}^{2+}$ sensor implicated in triggering vesicle fusion (i.e., in the $1 \mu \mathrm{M}$ rather than the $100 \mu \mathrm{M}$ range) (for review, see Zucker, 1996).

\section{Rab3 in synaptic plasticity}

Intracellular injection of the constitutively active apRab3-Q80L, which mimics an increase in endogenous GTP-bound Rab3, led to increased paired-pulse and train facilitation (Figs. 3-5). Moreover, paired-pulse facilitation increases at hippocampal CA1 excitatory synapses in mutant mice lacking Rab3A (Geppert et al., 1997). Hence, these two distinct approaches pinpoint an involvement of Rab3 in short-term synaptic facilitation. However, the role of Rab3 in facilitation may involve distinct actions: indeed, at Aplysia synapses, the increase in facilitation observed after apRab3-Q80L injection appears to result from a $\mathrm{Ca}^{2+}$-induced transient reduction in the GTP-Rab3 inhibitory action on neuroexocytosis, but obviously this explanation cannot apply when Rab3A is lacking. Moreover, Rab3A has been implicated in long-term potentiation at hippocampal mossy fibers (Castillo et al., 1997) but not at excitatory CA1 synapses (Geppert et al., 1994). Taken together, these observations indicate that the participation of Rab3 in the regulation of presynaptic efficacy and synaptic plasticity depends on the physiological conditions or the pattern of expression of its partners or both. As noted above, this is consistent with the identification of several effectors for Rab3 and the implication of Rab3 at several distinct steps of the exocytotic process (see above discussion).

Until recently, the identity of the targets that are affected by changes in residual $\mathrm{Ca}^{2+}$ has remained unclear. Several possibilities exist that are not mutually exclusive. For instance, the $\mathrm{Ca}^{2+}$-binding protein Frequenin has been proposed to participate in facilitation (Rivosecchi et al., 1994). More recently, changes in $\left[\mathrm{Ca}^{2+}\right]_{\mathrm{i}}$ have been observed to strongly modulate the binding of the N-type $\mathrm{Ca}^{2+}$ channel to syntaxin and SNAP-25 (Sheng et al., 1996). Moreover, intracellular injection of a peptide corresponding to the syntaxin binding domain of $\mathrm{Ca}^{2+}$ channels inhibits evoked neurotransmitter release but increases both paired-pulse facilitation and spontaneous release (Mochida et al., 1996). Hence, part of presynaptic facilitation may originate from modulation of the docking-fusion particle dynamics or the probability of opening of $\mathrm{Ca}^{2+}$ channels. In this paper, we present a set of functional data suggesting that a $\mathrm{Ca}^{2+}$-dependent modulation of GTP-bound Rab3 action or its partners may account for at least part of the short-term plasticity phenomena such as paired-pulse facilitation or train facilitation. This deduction is fully consistent with several recent papers that ascribe a role for Rab3 late in exocytosis (Johannes et al., 1996; Bean and Scheller, 1997; Geppert et al., 1997).

\section{REFERENCES}

Adler EM, Augustine GJ, Duffy SN, Charlton MP (1991) Alien intracellular calcium chelators attenuate neurotransmitter release at the squid giant synapse. J Neurosci 11:1496-1507.

Bao J-X, Kandel ER, Hawkins RD (1997) Involvement of pre- and postsynaptic mechanisms in posttetanic potentiation at Aplysia synapses. Science 275:969-973.

Bean AJ, Scheller RH (1997) Better late than never: a role for Rabs late in exocytosis. Neuron 19:751-754.

Bittner MA, Holz RW (1992) Kinetic analysis of secretion from permeabilized adrenal chromaffin cells reveals distinct components. J Biol Chem 267:16219-16225.

Borst JGG, Sakmann B (1996) Calcium influx and transmitter release at fast CNS synapse. Nature 383:431-434.
Blundon JA, Wright SN, Brodwick MS, Bittner GD (1993) Residual free calcium is not responsible for facilitation of neurotransmitter release. Proc Natl Acad Sci USA 90:9388-9392.

Calakos N, Scheller RH (1996) Synaptic vesicle biogenesis, docking and fusion: a molecular description. Physiol Rev 76:1-29.

Castillo PE, Janz R, Südhof TC, Tzounopoulos T, Malenka RC, Nicoll RA (1997) Rab3A is essential for mossy fibre long-term potentiation in the hippocampus. Nature 388:590-593.

Cornille F, Deloye F, Fournié-Zaluski MC, Roques BP, Poulain B (1995) Inhibition of neurotransmitter release by synthetic proline-rich peptides shows that the $\mathrm{N}$-terminal domain of vesicle-associated membrane protein/synaptobrevin is critical for neuro-exocytosis. J Biol Chem 270:16826-16832.

Darchen F, Zahraoui A, Hammel F, Monteils M-P, Tavitian A, Scherman D (1990) Association of the GTP-binding protein Rab3A with bovine adrenal chromaffin granules. Proc Natl Acad Sci USA 87:5692-5696.

Darchen F, Senyshyn J, Brondyk WH, Taatjes DJ, Holz RW, Henry J-P, Denizot J-P, Macara IG (1995) The GTPase rab3a is associated with large dense core vesicles in bovine chromaffin cells and rat PC12 cells. J Cell Sci 108:1639-1649.

Fischer von Mollard G, Mignery GA, Baumert M, Perin MS, Hanson TJ, Burger PM, Jahn R, Südhof TC (1990) Rab3 is a small GTP-binding protein exclusively localized to synaptic vesicles. Proc Natl Acad Sci USA 87:1988-1992.

Fischer von Mollard G, Südhof TC, Jahn R (1991) A small GTP-binding protein dissociates from synaptic vesicles during exocytosis. Nature 349:79-81.

Fischer von Mollard G, Stahl B, Khoklatchev A, Südhof TC, Jahn R (1994) Rab3C is a vesicle protein that dissociates from synaptic vesicles after stimulation of exocytosis. J Biol Chem 269:10971-10974.

Fossier F, Baux G, Tauc L (1983) Possible role of acetylcholinesterase in regulation of postsynaptic receptor efficacy at a central inhibitory synapse of Aplysia. Nature 301:710-712.

Fukui K, Sasaki T, Imazumi K, Matsuura Y, Nakanishi H, Takai Y (1997) Isolation and characterization of a GTPase activating protein specific for the Rab3 subfamily of small G proteins. J Biol Chem 272:4655-4658.

Gardner D (1971) Bilateral symmetry and interneuronal organization in the buccal ganglion of Aplysia. Science 173:550-553.

Geppert M, Bolshakov VY, Siegelbaum SA, Takei K, De Camilli P, Hammer RE, Südhof TC (1994) The role of Rab3A in neurotransmitter release. Nature 369:493-497.

Geppert M, Goda Y, Stevens CF, Südhof TC (1997) The small GTPbinding protein Rab3A regulates a late step in synaptic vesicle fusion. Nature 387:810-814.

Holz RW, Brondyk WH, Senter RA, Kuzion L, Macara IG (1994) Evidence for the involvement of Rab3a in $\mathrm{Ca}^{2+}$-dependent exocytosis from adrenal chromaffin cells. J Biol Chem 269:10229-10234.

Hsu S-F, Augustine GJ, Jackson MB (1996) Adaptation of $\mathrm{Ca}^{2+}$ triggered exocytosis in presynaptic terminals. Neuron 17:501-512.

Johannes L, Lledo P-M, Roa M, Vincent J-D, Henry J-P, Darchen F (1994) The GTPase Rab3a negatively controls calcium-dependent exocytosis in neuroendocrine cells. EMBO J 13:2029-2037.

Johannes L, Doussau F, Clabecq A, Henry J-P, Darchen F, Poulain B (1996) Evidence for a functional link between Rab3 and the SNARE complex. J Cell Sci 109:2875-2884.

Kamiya H, Zucker RS (1994) Residual $\mathrm{Ca}^{2+}$ and short-term plasticity. Nature 371:603-606.

Katz B, Mildedi R (1968) The role of calcium in neuromuscular facilitation. J Physiol (Lond) 195:481-492.

Kretz R, Shapiro E, Kandel ER (1982) Posttetanic potentiation at an identified synapse in Aplysia is correlated with a $\mathrm{Ca}^{2+}$-activated $\mathrm{K}^{+}$ current in the presynaptic neuron: evidence for $\mathrm{Ca}^{2+}$ accumulation. Proc Natl Acad Sci USA 79:5430-5434.

Li C, Takei K, Geppert M, Daniell L, Stenius K, Chapman ER, Jahn R, De Camilli P, Südhof TC (1994) Synaptic targeting of Rabphilin-3A, a synaptic vesicle $\mathrm{Ca}^{2+} /$ phospholipid-binding protein, depends on rab3A/3C. Neuron 13:885-898.

Lledo P-M, Vernier P, Vincent J-D, Mason WT, Zorec R (1993) Inhibition of Rab3B expression attenuates $\mathrm{Ca}^{2+}$-dependent exocytosis in rat anterior pituitary cells. Nature 364:540-544.

Mallart A, Martin AR (1967) An analysis of facilitation of transmitter release at the neuromuscular junction of the frog. J Physiol (Lond) 193:593-604.

Martincic I, Reralta ME, Ngsee JK (1997) Isolation and characteriza- 
tion of a dual prenylated rab and VAMP/2 acceptor. J Biol Chem 272:26991-26998.

Matthews G (1996) Neurotransmitter release. Annu Rev Neurosci 19:219-233.

McKiernan CJ, Brondyk WH, Macara IG (1993) The Rab3A GTPase interacts with multiple factors through the same effector domain: mutational analysis of cross-linking of Rab3A to a putative target protein. J Biol Chem 268:24449-24452.

Mochida S, Sheng Z-H, Baker C, Kobayashi H, Catterall WA (1996) Inhibition of neurotransmission by peptides containing the synaptic protein interaction site of the N-type $\mathrm{Ca}^{2+}$ channels. Neuron 17:781-788.

Nonet ML, Staunton JE, Kilgard MP, Fergerstad T, Hartwieg E, Horvitz HR, Jorgensen EM, Meyer BJ (1997) Caenorhabditis elegans rab-3 mutant synapses exhibit impaired function. J Neurosci 17:8061-8073.

Novick P, Zerial M (1997) The diversity of Rab proteins in vesicle transport. Curr Opin Cell Biol 9:496-504.

Park JB, Farnsworth CC, Glomset JA (1997) $\mathrm{Ca}^{2+} /$ calmodulin causes Rab3A to dissociate from synaptic membranes. J Biol Chem 272:20857-20865.

Regazzi R, Ravazzola M, Iezzi M, Lang J, Zahraoui A, Andereggen E, Morel P, Takai Y, Wollheim CB (1996) Expression, localisation and functional role of small GTPases of the Rab3 family in insulin-secreting cells. J Cell Sci 109:2265-2273.

Rivosecchi R, Pongs O, Theil T, Mallart A (1994) Implication of frequenin in the facilitation of transmitter release in Drosophila. J Physiol (Lond) 474:223-232.

Rybin V, Ullrich O, Rubino M, Alexandrov K, Simon I, Seabra MC, Goody R, Zerial M (1996) GTPase activity acts as a timer for endocytic membrane fusion. Nature 38:266-269.

Sheng Z-H, Rettig J, Cook T, Catterall WA (1996) Calcium-dependent interaction of $\mathrm{N}$-type calcium channels with the synaptic core complex. Nature 379:451-454.

Shirataki H, Kaibuchi K, Yamaguchi T, Wada K, Horiuchi H, Takai Y
(1992) A possible target protein for smg-25A/rab3A small GTPbinding protein. J Biol Chem 267:10946-10949.

Simonneau M, Tauc L, Baux G (1980) Quantal release of acetylcholine examined at identified neuro-neuronal synapse of Aplysia. Proc Natl Acad Sci USA 77:1661-1665.

Stahl B, Von Mollard GF, Walchsolimena C, Jahn R (1994) GTP cleavage by the small GTP-binding protein Rab3A is associated with exocytosis of synaptic vesicles induced by alpha-latrotoxin. J Biol Chem 269:24770-24776.

Südhof TC (1995) The synaptic vesicle cycle: a cascade of proteinprotein interactions. Nature 375:645-653.

Südhof TC (1997) Function of Rab3 GDP-GTP exchange. Neuron 18:519-522.

Swandulla D, Hans M, Zipser K, Augustine G (1991) Role of residual calcium in synaptic depression and posttetanic potentiation: fast and slow calcium signaling in nerve terminals. Neuron 7:915-926.

Van der Kloot W, Molgó J (1994) Quantal acetylcholine release at the vertebrate neuromuscular junction. Physiol Rev 74:899-991.

Wang Y, Okamoto M, Schmitz F, Hofmann K, Südhof TC (1997) Rim is a putative Rab3 effector in regulating synaptic-vesicle fusion. Nature 388:593-598.

Weber E, Jilling T, Kirk KL (1996) Distinct functional properties of Rab3A and Rab3B in PC12 neuroendocrine cells. J Biol Chem 271:6963-6971.

Yamaguchi T, Shirataki H, Kishida S, Miyasaki M, Nishikawa J, Wada K, Numata S, Kaibuchi K, Takai Y (1993) Two functionally different domains of Rabphilin-3A, Rab3A p25/smg p25A-binding and phospholipid- and $\mathrm{Ca}^{2+}$-binding domains. $\mathrm{J}$ Biol Chem 268:27164-27170.

Zucker RS (1989) Short-term synaptic plasticity. Annu Rev Neurosci 12:13-31.

Zucker RS (1996) Exocytosis: a molecular and physiological perspective. Neuron 17:1049-1055. 